\title{
Evaluation of the rheological behaviour of Warm Mix Asphalt (WMA) modified binders
}

\author{
H.M.R.D. Silva, J.R.M. Oliveira \& E.J. Peralta \\ University of Minho, Guimarães, Portugal \\ C.I.G. Ferreira \\ Construções Gabriel A.S. Couto S.A., Vila Nova de Famalicão, Portugal
}

\begin{abstract}
Several processes and products are available to produce warm mix asphalt (WMA). The use of those may reduce the mixing and compaction temperatures in relation to hot mix asphalt (HMA), ensuring a good performance of the pavement. Lower plant mixing temperatures mean reduction in fuel consumption and lower emissions, what may contribute to diminish odours and health problems. A laboratory study on the properties of the modified binders (using two commercial WMA additives-Sasobit ${ }^{\circledR}$ and Cecabase ${ }^{\circledR}$ ) was carried out through conventional (penetration, softening point), dynamic viscosity and rheology (DSR) tests, in order to establish the optimum additive content. Stripping of binder from the aggregates is a reported problem in WMA. Thus, the affinity of the modified binders was assessed without encountering significant problems. It was also observed that only Sasobit ${ }^{\circledR}$ alters the viscosity of the binder. A maximum temperature reduction of $15^{\circ} \mathrm{C}$ was achieved using $4 \%$ of Sasobit ${ }^{\circledR}$ with a softer binder.
\end{abstract}

\section{INTRODUCTION}

Nowadays one of the most important challenges for our society is the necessary reduction in the consumption of fuel, with the corresponding reduction in the emission of greenhouse gases (GHG). For the production of bituminous mixtures, several new technologies have been developed, and increasingly applied, in order to reduce the temperature of production and application on site of the mixtures. Generally, these technologies refer to the production of WMA which can be developed for all types of bituminous mixtures, including dense, continuously and gap-graded mixtures, applied in different thicknesses and in roads with different traffic levels.

In the present study, the potential of one of the techniques of WMA is analysed, comprising the modification of the binder, by the use of additives, in order to reduce the viscosity and to ensure adequate conditions of mixture and compaction at temperatures slightly above $100^{\circ} \mathrm{C}$. Thus, a study of the properties of the modified binder was initially carried out for two commercial additives (Sasobit ${ }^{\circledR}$ and Cecabase $^{\circledR}$ ), by adding different quantities of each and determining their influence on the properties of the resulting binder.

This study is part of an ongoing project where the performance of two WMA mixtures will be compared with the performance of a traditional mixture of similar composition. Presently, only the results of the binder properties and their affinity to the aggregates are available and presented in the following sections.

\section{LITERATURE REVIEW ON WARM MIX ASPHALT}

Reducing the environmental impacts caused by the industrial activities is a basic condition to adapt the new circumstances of development to the present requests of sustainability. 
The emissions resulting from the production of Hot Mix Asphalts (HMA) can vary significantly depending on the materials selected, equipment or production modes.

The life cycle of a road pavement can be divided into four stages: (i) the manufacturing of materials used for its construction; (ii) the construction of the pavement itself; (iii) the maintenance/rehabilitation of its condition; (iv) the demolition or recycling of the pavement. According to Park et al. (2003), the environmental load of each of these stages can be estimated by applying an environmental emissions factor related to the source of the energy consumed. These authors also refer that most of the energy is consumed in the manufacturing stage of construction materials (and consequently most of the emissions are produced in that stage).

In this context, innumerable potential benefits in the use of WMA has legitimated its emergent development, especially if considering the lower amount of energy necessary for the production of the mixtures, what implies significant reduction in the GHG emission values. Typical expected reductions are 30 to 40 percent for $\mathrm{CO}_{2}$ and sulphur dioxide $\left(\mathrm{SO}_{2}\right)$, 50 percent for volatile organic compounds (VOC), 10 to 30 percent for carbon monoxide (CO), 60 to 70 percent for nitrous oxides (NOx) and 20 to 25 percent for dust. Likewise savings that can reach $35 \%$ in the amount of fuel consumed in the burner devices for warming the aggregates are an important argument. On the other hand, in what respects to the application of the mixture on site, its lower production temperature allows for the compaction of the mixture at a lower temperature, without compromising the desired densities of the resulting layers. The reduction in the exposition to fumes by the workers is another important advantage of this type of mixtures, with values 30 to $50 \%$ lower in relation to those released by conventional mixtures (D'Angelo et al., 2008).

Warm mix asphalts also allow longer haul distances, a longer construction season and minimized oxidative hardening, since the mixes are produced closer to the operating temperatures. Several processes have been developed with the objective of reducing the temperature of production and compaction of bituminous mixtures, apparently without compromising their performance. However, the use of lower compaction temperatures when producing warm asphalt may increase the potential for moisture damage (Hurley and Prowell, 2006).

For the WMA mixtures to be accepted in the national and international market, it is essential that the performance of those mixtures can be compared to that of the conventional HMA mixtures and that the environmental benefits and the reduction in energy consumption can compensate the slightly higher costs of the WMA mixtures (due to the cost of the additives).

\section{BINDER PRODUCTION AND CHARACTERISATION}

\subsection{Original binders and additives used}

In the present study, three paving grade bitumens and two additives were used with the objective of determining the most appropriate binder constitution for the production of a Warm Mix Asphalt adapted to the Portuguese conditions.

The three paving grade bitumens used are a B35/50, a B50/70 and a B100/150 pen bitumen (classified according to the European Standard EN 12591). For the "modification" of these bitumens, two commercial additives, known as "Cecabase ${ }^{\circledR}$ " and "Sasobit ${ }^{\mathbb{1}}$ ", were used in controlled amounts in order to determine their influence on the final binder properties.

Cecabase $^{\circledR}$ is an additive containing surface active agents that, when mixed with asphalt, allows a reduction on the road surface application temperature of about $50^{\circ} \mathrm{C}$ with no effect on performance of the material. Compared to the classical paving process, the use of this additive reduces energy consumption by 20 to $50 \%$, depending on the process, and considerably reduces dust emission (CECA, 2008). According to the producers, the incorporation of this additive in the production of bituminous mixtures ( 2 to $4 \mathrm{~kg}$ per tonne of asphalt binder) enables the application temperature to be reduced to $120^{\circ} \mathrm{C}$ and, at the same time, it enables the WMA layer to retain the same properties as a classical layer with $\mathrm{HMA}$ produced at $160-180^{\circ} \mathrm{C}$.

Sasobit ${ }^{\circledR}$ is a Fischer-Tropsch (F-T) or synthetic wax that is created during the coal gasification process and that has been used as a compaction aid and a temperature reducer. The Sasobit ${ }^{\circledR}$ process incorporates a low melting point organic additive that chemically 
changes the temperature-viscosity curve of the binder (Button et al., 2007). Sasobit ${ }^{\circledR}$ melts at approximately $100^{\circ} \mathrm{C}$ and significantly reduces the viscosity of the base bitumen. It increases the asphalt resistance to deformation throughout the operating temperature range without affecting the low temperature properties of the mixture, which are determined by the characteristics of the base bitumen (Sasol, 2008). Sasobit ${ }^{\circledR}$ is completely soluble in bitumen at temperatures above $115^{\circ} \mathrm{C}$. It forms a homogeneous solution with base bitumen on stirring reducing remarkably its viscosity. This also enables mixing and reducing by $10-30^{\circ} \mathrm{C}$ the handling temperatures of the asphalt (Sasol Wax GmbH, 2004). According to Hurley and Prowell (2005), Sasobit ${ }^{\circledR}$ has shown to improve the compactability of mixtures in both the shear gyratory compactor and vibratory compactor. Statistics indicated an overall reduction in air voids. Improved compaction was noted at temperatures as low as $190^{\circ} \mathrm{F}\left(88^{\circ} \mathrm{C}\right)$. The addition of Sasobit ${ }^{\circledR}$ does not affect the resilient modulus of an asphalt mix nor does it increase the rutting potential of asphalt mixtures.

\subsection{Production of the "modified" binders}

Thirteen samples of modified binders were prepared in the laboratory for a thorough characterisation (penetration, softening point, dynamic viscosity and rheology). These samples comprised the addition of three percentages of each additive to the B35/50 and the B50/70 bitumens and one percentage $(4 \%)$ of Sasobit ${ }^{\circledR}$ to the B100/150 bitumen. Based on the recommendations of the additive producers, 2,3 and $4 \%$ of Sasobit ${ }^{\circledR}$ and $0.2,0.3$ and $0.4 \%$ of Cecabase ${ }^{\circledR}$ were added to the two conventional bitumens.

In order to determine the optimum additive content, several tests were carried out on the resulting binders as explained in the following sections.

The modified binders were obtained by mixing each bitumen with the additive for a period of five minutes at a temperature of $130^{\circ} \mathrm{C}$.

\subsection{Basic characterization of the binders}

In order to classify the binders used in this study, a basic characterisation was performed in accordance with the EN 12591 standard. This included the tests of penetration at $25^{\circ} \mathrm{C}$ (following the EN 1426 standard) and of softening point (also known as Ring \& Ball

Table 1. Results obtained for the penetration at $25^{\circ} \mathrm{C}$ and softening point of the binders.

\begin{tabular}{|c|c|c|c|c|c|c|c|c|}
\hline Bitumen & $\begin{array}{l}\text { Additive } \\
\text { type }\end{array}$ & $\begin{array}{l}\text { Amount } \\
\%\end{array}$ & $\begin{array}{l}\text { Pen } \\
(\mathrm{dmm})\end{array}$ & $\begin{array}{l}\Delta_{\text {Pen }} \\
(\mathrm{dmm})\end{array}$ & $\begin{array}{l}\Delta_{\text {Pen }} \\
(\%)\end{array}$ & $\begin{array}{l}\mathrm{R} \& \mathrm{~B} \\
\left({ }^{\circ} \mathrm{C}\right)\end{array}$ & $\begin{array}{l}\Delta_{\mathrm{R} \& \mathrm{~B}} \\
\left({ }^{\circ} \mathrm{C}\right)\end{array}$ & $\begin{array}{l}\Delta_{\mathrm{R \& B}} \\
(\%)\end{array}$ \\
\hline \multirow[t]{7}{*}{ B35/50 } & None & & 41.3 & 0.0 & $0 \%$ & 56.7 & 0.0 & $0 \%$ \\
\hline & \multirow[t]{3}{*}{ Sasobit $^{\circledR}$} & 2 & 32.0 & -9.3 & $-22 \%$ & 72.6 & 16.0 & $28 \%$ \\
\hline & & 3 & 33.1 & -8.2 & $-20 \%$ & 81.5 & 24.9 & $44 \%$ \\
\hline & & 4 & 28.6 & -12.6 & $-31 \%$ & 91.9 & 35.3 & $62 \%$ \\
\hline & \multirow[t]{3}{*}{ Cecabase $^{\circledR}$} & 0.2 & 44.9 & 3.6 & $9 \%$ & 55.8 & -0.9 & $-2 \%$ \\
\hline & & 0.3 & 41.8 & 0.5 & $1 \%$ & 55.4 & -1.3 & $-2 \%$ \\
\hline & & 0.4 & 43.0 & 1.7 & $4 \%$ & 55.4 & -1.3 & $-2 \%$ \\
\hline \multirow[t]{7}{*}{ B50/70 } & \multirow{4}{*}{$\begin{array}{l}\text { None } \\
\text { Sasobit }^{\circledR}\end{array}$} & & 58.9 & 0.0 & $0 \%$ & 51.6 & 0.0 & $0 \%$ \\
\hline & & 2 & 45.2 & -13.7 & $-23 \%$ & 69.7 & 18.1 & $35 \%$ \\
\hline & & 3 & 41.4 & -17.5 & $-30 \%$ & 81.5 & 29.9 & $58 \%$ \\
\hline & & 4 & 36.6 & -22.3 & $-38 \%$ & 87.5 & 36.0 & $70 \%$ \\
\hline & \multirow[t]{3}{*}{ Cecabase $^{\circledR}$} & 0.2 & 61.1 & 2.3 & $4 \%$ & 51.1 & -0.4 & $-1 \%$ \\
\hline & & 0.3 & 63.6 & 4.8 & $8 \%$ & 50.6 & -1.0 & $-2 \%$ \\
\hline & & 0.4 & 63.6 & 4.8 & $8 \%$ & 50.1 & -1.5 & $-3 \%$ \\
\hline \multirow[t]{2}{*}{ B100/150 } & None & & 143.4 & 0.0 & $0 \%$ & 44.3 & 0.0 & $0 \%$ \\
\hline & Sasobit $^{\circledR}$ & 4 & 68.4 & -75.1 & $-52 \%$ & 87.0 & 42.8 & $97 \%$ \\
\hline
\end{tabular}



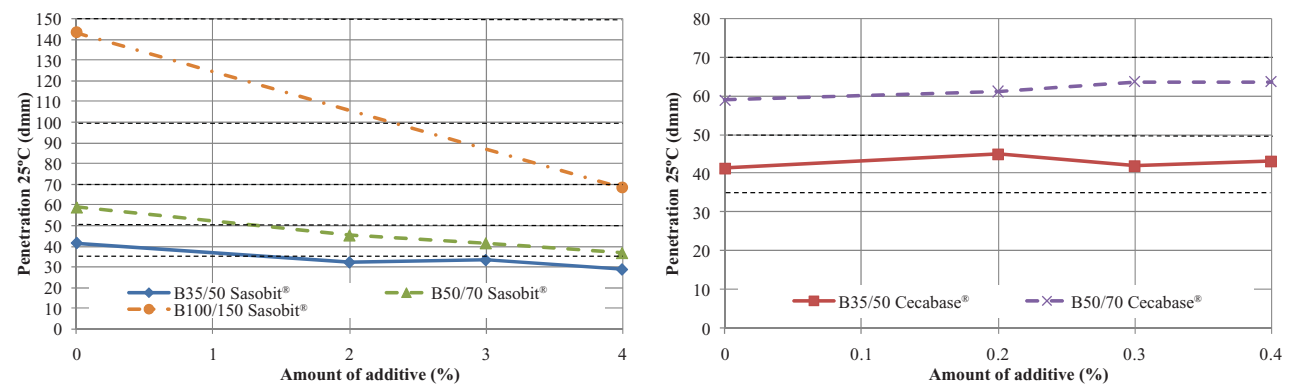

Figure 1. Evolution of the penetration value of the binders with the amount of additive.
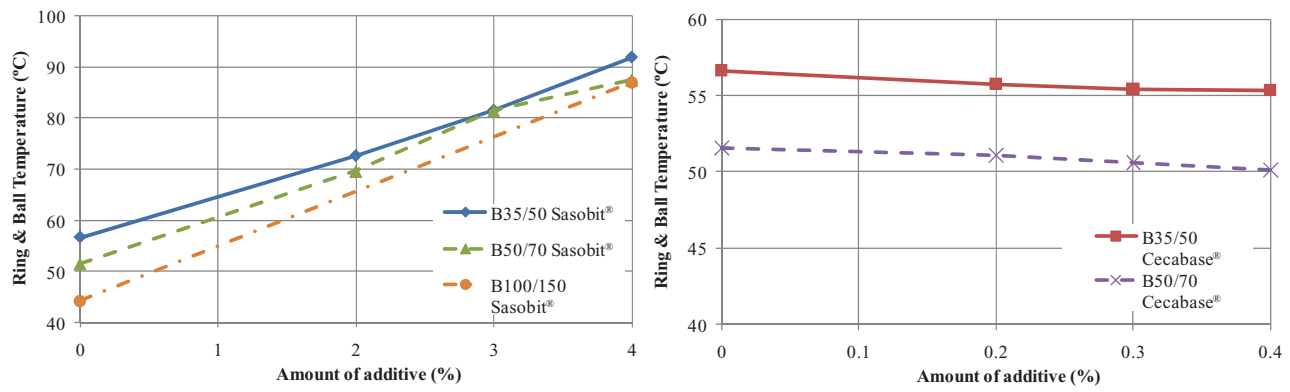

Figure 2. Evolution of the softening point of the binders with the amount of additive.

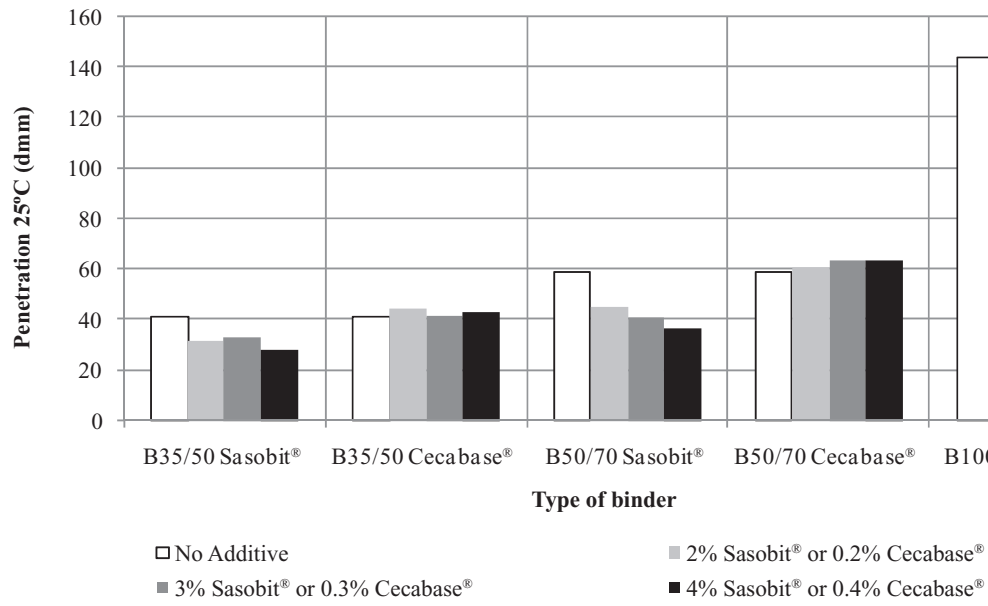

Figure 3. Influence of the amount and type of additive on the penetration value of the binders.

temperature, R\&B, according to the EN 1427 standard). The results obtained for the paving grade bitumens and for those obtained by the addition of a certain amount of additive are summarised in Table 1.

The results presented in Table 1 are graphically illustrated in Figures 1 to 5. In Figures 1 and 2, the evolution of the values of penetration at $25^{\circ} \mathrm{C}$ and softening point with the amount of additive used in each paving grade bitumen (B35/50, B50/70 and B100/150) can be observed. For the latter, only the addition of $4 \%$ Sasobit ${ }^{\circledR}$ was considered. 


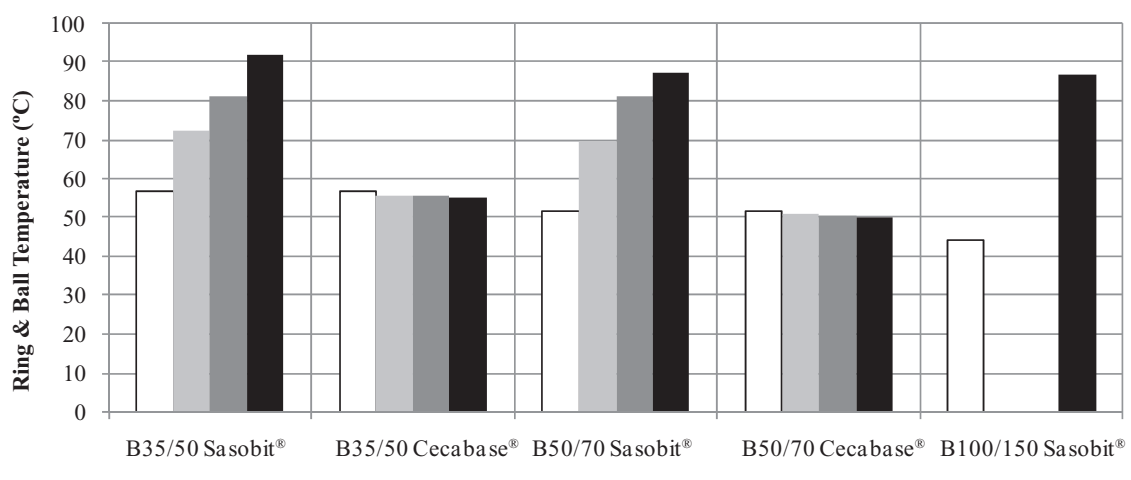

Type of binder

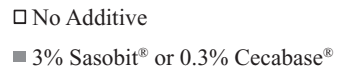

$2 \%$ Sasobit $^{\circledR}$ or $0.2 \%$ Cecabase $^{\circledR}$

- $4 \%$ Sasobit ${ }^{\mathbb{B}}$ or $0.4 \%$ Cecabase $^{\sqrt{B}}$

Figure 4. Influence of the amount and type of additive on the softening point of the binders.
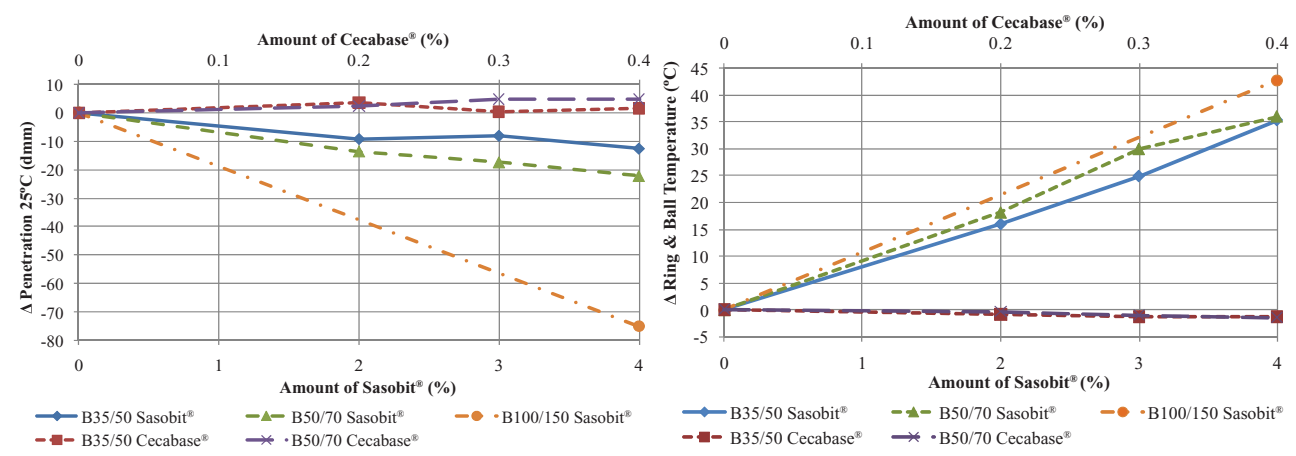

Figure 5. Variation observed in the values of penetration and softening point of the binders.

As can be seen from Figures 1 and 2, the addition of up to $0.4 \%$ of Cecabase $^{\circledR}$ to the original bitumens does not change their classification (their penetration and R\&B temperature is barely altered) while the addition of Sasobit ${ }^{\circledR}$ significantly modifies their properties (they can be classified as hard binder types, changing the penetration grade). This is easily observed, for example, from the addition of $4 \%$ Sasobit $^{\circledR}$ to the $100 / 150$ pen bitumen. Its classification changed to a $50 / 70$ pen bitumen ( 2 grades difference) in terms of penetration at $25^{\circ} \mathrm{C}$ and to a much harder bitumen in terms of softening point $\left(87^{\circ} \mathrm{C}\right.$, while a normal $20 / 30$ pen bitumen has a softening point between 55 and $63^{\circ} \mathrm{C}$ ). This is depicted in Figures 3 and 4 , where the influence of the amount of additive in the properties of the binders is illustrated.

Figure 5 shows the variation of the values of penetration and softening point obtained for the studied binders. In this figure, it is clear that Cecabase ${ }^{\circledR}$ has negligible influence on the properties of the "modified" binders while Sasobit ${ }^{\circledR}$ has a great influence on the mentioned properties.

\subsection{Dynamic viscosity of the binders in the rotating spindle apparatus}

In order to evaluate the properties of the several binders at higher temperatures $\left(100\right.$ to $\left.170^{\circ} \mathrm{C}\right)$ in which the bituminous mixtures are mixed and applied, their dynamic viscosity was accessed using a rotating spindle apparatus (according to the EN 13302 standard). The typical temperature of a coaxial viscometer using a rotating spindle apparatus is ranged from 50 to $250^{\circ} \mathrm{C}$. 


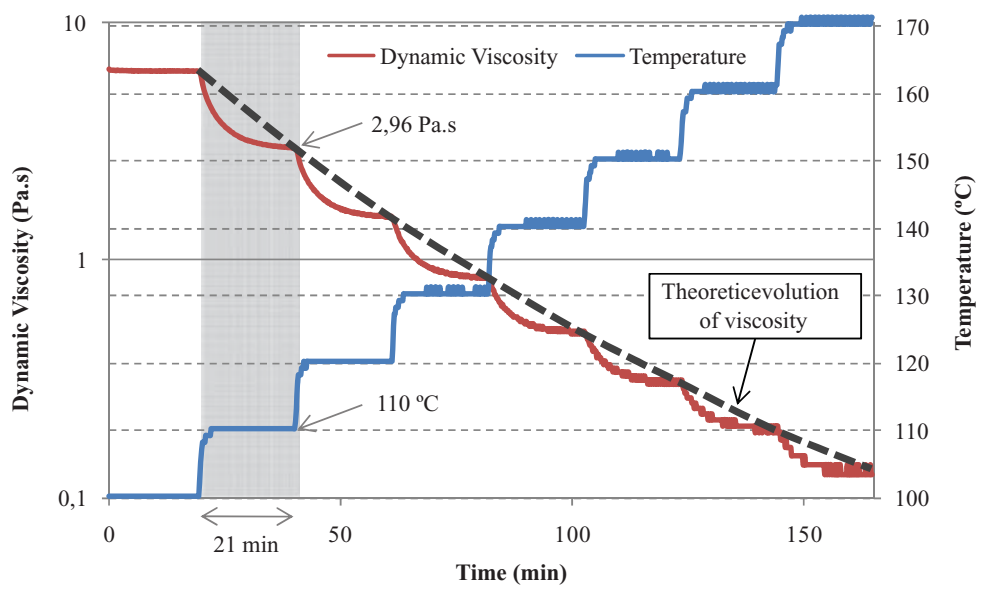

Figure 6. Method used to assess the viscosity at different temperatures in a rotating spindle apparatus.

During the test, the torque (relative resistance of the spindle to rotation) applied to a spindle rotating in a special sample container enclosing the binder measured its dynamic viscosity. According to EN 13302, after setting the test temperature and lowering the spindle into the binder, the system temperature should equilibrate after 15 to 30 min (lab practice showed that the usual equilibrium time is $18 \mathrm{~min}$ ). Then, at least three readings were taken during the next $3 \mathrm{~min}$ for each evaluated temperature. The dynamic viscosity at each temperature is the arithmetic mean of the three readings taken between the 18th and 21 st min of the test.

Figure 6 summarizes the method used to evaluate the dynamic viscosity of the binders at different temperatures, where the shaded area exemplifies the determination of the dynamic viscosity $(2.96 \mathrm{~Pa} . \mathrm{s})$ at a temperature of $110^{\circ} \mathrm{C}$. The dashed line would represent the theoretical evolution of dynamic viscosity if the test temperature had been increased gradually from 110 to $170^{\circ} \mathrm{C}$. It can also be observed that the viscosity reached an equilibrium value, at every test temperature, just about after 21 min (18 plus $3 \mathrm{~min}$ ), as stated previously.

The theoretical evolution of the dynamic viscosity of the several binders with the test temperature is the final result of the tests carried out to analyse the optimum amount of additive, both Sasobit ${ }^{\circledR}$ and Cecabase $^{\circledR}$, necessary to mix and apply the WMA at lower temperatures.

The evolution of the dynamic viscosity with the temperature for different types of paving grade bitumens (B35/50, B50/70 and B100/150), before and after their modification with WMA additives, can be observed in Figures 7 and 8 respectively, for the Sasobit ${ }^{\circledR}$ and Cecabase ${ }^{\circledR}$ modified binders. Although other amounts of additive were used to modify the bitumen, only some values are presented ( 2 and $4 \%$ ) to demonstrate the evolution of the viscosity when different quantities of Sasobit ${ }^{\circledR}$ are used. For the Cecabase ${ }^{\circledR}$ modified binders, only the maximum addition of $0.4 \%$ is presented, in order to make the figures clearer.

Figure 7 shows that the addition of Sasobit ${ }^{\circledR}$ reduces the dynamic viscosity of the binder at production and application temperatures. Even though one of the objectives of using Sasobit ${ }^{\circledR}$ in WMAs is to reduce application temperatures, changes observed at these temperatures are lower than those observed at in service conditions (penetration and R\&B). After analysing the temperatures at the limit equal-viscosity line for mixing $(0.2 \mathrm{~Pa} . \mathrm{s})$, it can be concluded that the addition of $2 \%$ of Sasobit ${ }^{\circledR}$ allows reducing 2 to $4{ }^{\circ} \mathrm{C}$ in comparison with the neat bitumens, while the binders modified with $4 \%$ Sasobit ${ }^{\circledR}$ presented higher reductions ( 7 to $9^{\circ} \mathrm{C}$ ).

A $50 / 70$ pen binder modified with $4 \%$ of Sasobit ${ }^{\circledR}$ can be considered as a $35 / 50$ bitumen at operating conditions (based on the penetration and R\&B results and on EN 12591), as 


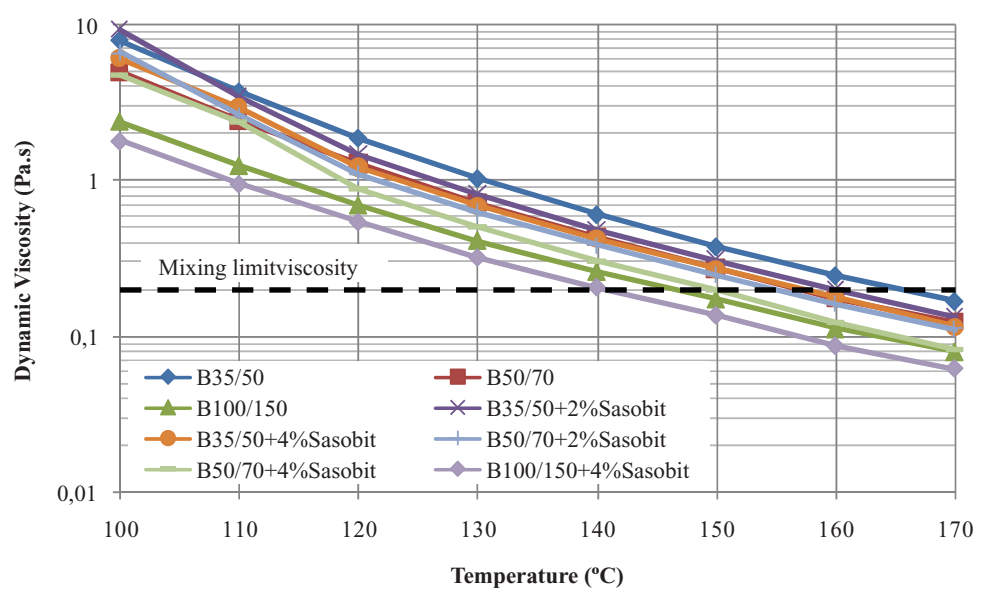

Figure 7. Dynamic viscosity of the Sasobit ${ }^{\circledR}$ modified binders (rotating spindle apparatus).

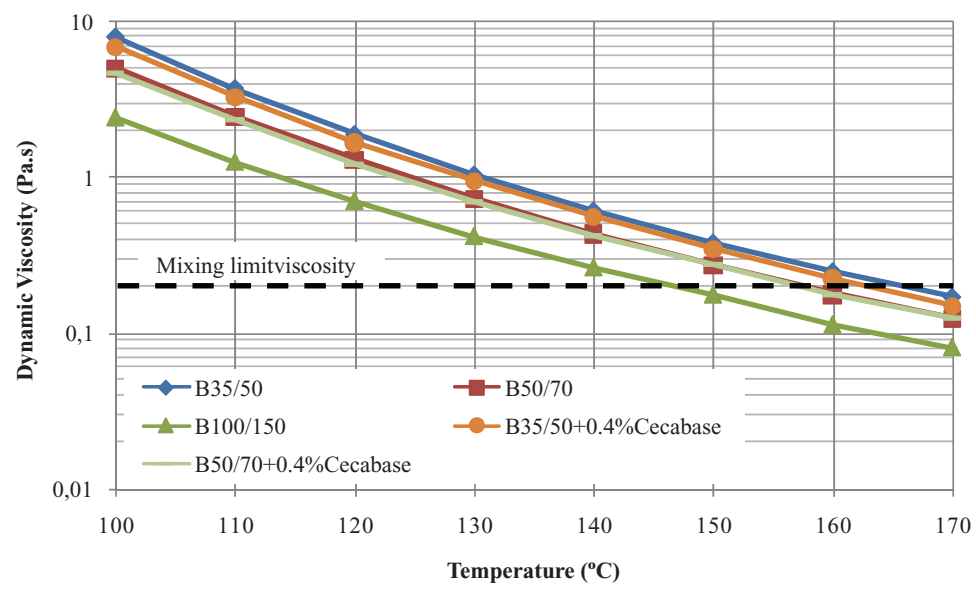

Figure 8. Dynamic viscosity of the Cecabase ${ }^{\circledR}$ modified binders (rotating spindle apparatus).

well as a $100 / 150$ pen binder modified with $4 \%$ of Sasobit ${ }^{\circledR}$ can be considered as a $50 / 70$ bitumen. When analysing the reduction of the mixing temperature at the equal-viscosity line of $0.2 \mathrm{~Pa}$.s for these "equivalent" binders, a reduction of 15 to $17^{\circ} \mathrm{C}$ can be observed. Based on the main objective of WMA mixtures, it was concluded that the maximum temperature reduction was achieved using $4 \%$ of Sasobit ${ }^{\circledR}$ with softer bitumens $(50 / 70$ or $100 / 150)$, and thus these binders were further characterized through rheological testing (as presented in the following section).

Figure 8 shows that the addition of up to $0.4 \%$ of Cecabase ${ }^{\circledR}$ to the original bitumen barely changes its dynamic viscosity at the typical application temperatures. In fact, a minor reduction of viscosity can be observed (only in the $35 / 50$ pen bitumen) after the addition of $0.4 \%$ of Cecabase ${ }^{\circledR}$ that allows a reduction of only $2^{\circ} \mathrm{C}$ in the equal-viscosity line of $0.2 \mathrm{~Pa}$.s. Cecabase ${ }^{\circledR}$ additive does not change the binder properties (penetration, R\&B temperature and viscosity) at the studied temperatures, and so the rheology of this modified binder will not be further characterized. In fact, Cecabase ${ }^{\circledR}$ is a chemical additive that acts as a surface active agent, improving the mixing workability at lower temperatures. The selection of the optimum amount of Cecabase ${ }^{\circledR}$ additive must result from further studies carried out on WMA mixtures. 


\section{RHEOLOGICAL CHARACTERISATION OF THE MODIFIED BINDERS}

\subsection{Methodology used}

In order to determine the changes of the binders due to the addition of Sasobit ${ }^{\circledR}$, three bitumens (35/50, 50/70 and 100/150), three modified binders (50/70 with 2 and $4 \%$ of Sasobit ${ }^{\circledR}$ and $100 / 150$ with $4 \%$ of Sasobit ${ }^{\circledR}$ ) and the Sasobit ${ }^{\circledR}$ additive were tested in a Dynamic Shear Rheometer (DSR) capable of measuring the rheology of these materials (EN 14770 standard).

Measurement of the rheological properties of the binders was carried out in a rotational DSR with parallel plate sample geometries of $40 \mathrm{~mm}$ and $1 \mathrm{~mm}$ gap (with manual gap compensation at each test temperature). The rheometer was set up to test in an oscillatory mode so as to guarantee a dynamic response from the specimen, ensuring that the specimen was tested in the linear region over the temperature $\left(25\right.$ to $\left.170^{\circ} \mathrm{C}\right)$ and frequency range selected $(0.1$ to $10 \mathrm{~Hz})$. Thus, preliminary tests were carried out at different temperatures and frequencies in order to select stress values at which the binders are in the linear range (properties must not differ by more than $5 \%$ of their value over the stress range chosen). Based on this preliminary study, the stress values selected to carry out the DSR tests varied between $1000 \mathrm{~Pa}$ at $25^{\circ} \mathrm{C}$ and $3 \mathrm{~Pa}$ at $170^{\circ} \mathrm{C}$.

The DSR tests began at the lowest selected temperature, starting at the lowest frequency and proceeding to the highest. After the completion of each test temperature, it was possible to proceed to the next temperature at a rate not beyond $5^{\circ} \mathrm{C}$ per minute. During the test, the selected oscillatory shear stress is applied to the specimen and the resulting shear strain is measured.

\subsection{Results obtained}

The final results of the test involved determining the norm of the complex shear modulus $\left(\left|\mathrm{G}^{*}\right|\right.$ - ratio between peak stress and peak strain) and the phase angle ( $\delta$-phase difference between stress and strain) of the binders over a range of test frequencies and test temperatures. These results are presented in Figure 9 for bitumen 50/70 (before and after adding 4\% of Sasobit ${ }^{\circledR}$ ) and for pure Sasobit ${ }^{\circledR}$ additive so as to exemplify the rheological changes verified due to the use of this additive. Other result obtained from the DSR test is the dynamic viscosity of the material, which is presented in Figure 10 for an original bitumen, a modified binder and the Sasobit ${ }^{\circledR}$.

The complex shear modulus of Sasobit ${ }^{\circledR}$ is very high $(1 \mathrm{MPa})$, constant and independent of the frequency before its congealing temperature $\left(102^{\circ} \mathrm{C}\right)$, behaving essentially as an elastic solid material. Slightly above that temperature the complex modulus decreases very quickly and Sasobit ${ }^{\circledR}$ becomes a liquid material with some residual viscoelasticity that is much more directly frequency dependent. The dynamic viscosity of Sasobit ${ }^{\circledR}$ has an evolution similar to its complex modulus, except for its variation with the frequency before $102^{\circ} \mathrm{C}$.
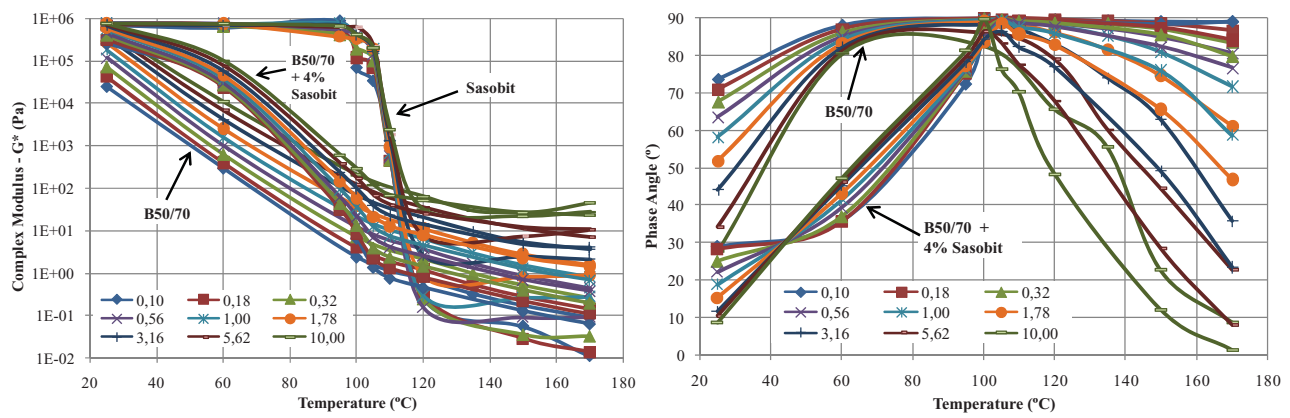

Figure 9. Rheology of a Sasobit ${ }^{\circledR}$ modified binder at different temperatures and frequencies (DSR). 
It was noticed that at lower temperatures, usually below $100^{\circ} \mathrm{C}$ (while the materials have viscoelastic behaviour and have not yet become liquid), all the tested materials presented higher viscosities for lower frequencies, the opposite occurring at higher temperatures.

The complex modulus of the studied binders significantly changes for different test temperatures and frequencies. At $25^{\circ} \mathrm{C}$ the complex modulus of the original bitumen is slightly lower than that of Sasobit ${ }^{\circledR}$ (being almost equal at $10 \mathrm{~Hz}$, but quite lower at $0.1 \mathrm{~Hz}$ ). This difference increases for higher operating temperatures (between 50 and $90^{\circ} \mathrm{C}$ ), which justifies the great raise of the $\mathrm{R} \& \mathrm{~B}$ temperature of the binders modified with Sasobit ${ }^{\circledR}$. Above $115^{\circ} \mathrm{C}$ the original bitumen has a complex modulus only slightly higher than that of Saso$\mathrm{bit}^{\circledR}$, being this difference insufficient to allow a great reduction of the WMAs production temperature (the necessary reduction of temperature only occurs when using a softer binder to produce the modified binder). The dynamic viscosity of the original bitumen barely varies for different test frequencies, but the phase angle is very dependent on the frequency (being the behaviour more elastic for higher frequencies). It was observed that the bitumen has a viscoelastic behaviour at operating temperatures $\left(25\right.$ to $\left.60^{\circ} \mathrm{C}\right)$, then it mainly presents a viscous behaviour with a residual elasticity $\left(60\right.$ to $\left.100^{\circ} \mathrm{C}\right)$ and finally it behaves like a liquid, with a decrease of the phase angle due to reduction of the viscous modulus into residual values similar to the elastic modulus.

The rheology of the binder modified with Sasobit ${ }^{\circledR}$ is based essentially on the behaviour of the original bitumen, which is modified by Sasobit ${ }^{\circledR}$ mainly at temperatures between

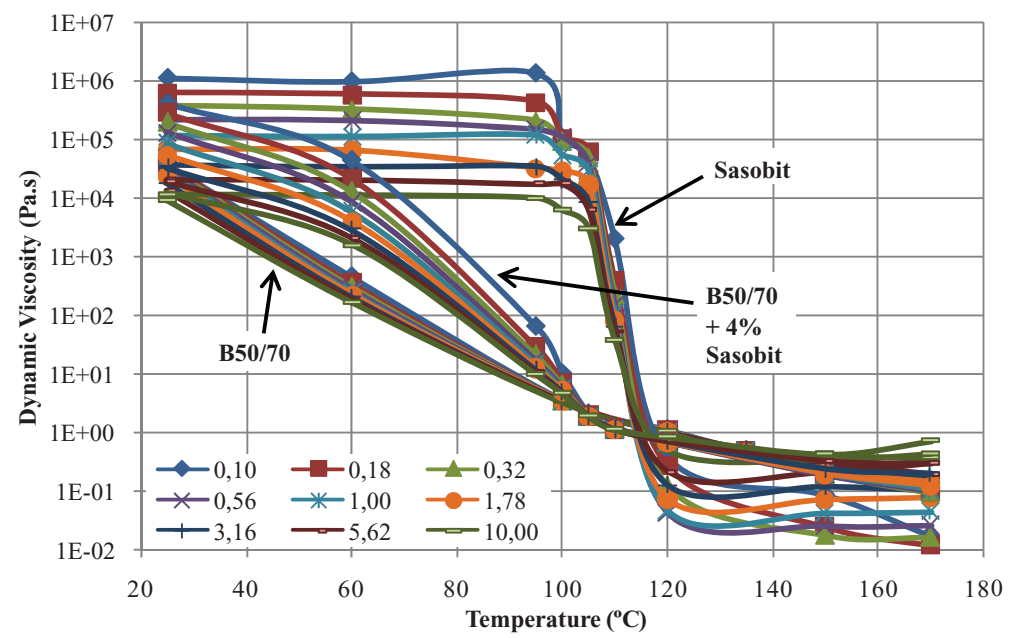

Figure 10. Viscosity of a Sasobit ${ }^{\circledR}$ modified binder at different temperatures and frequencies (DSR).
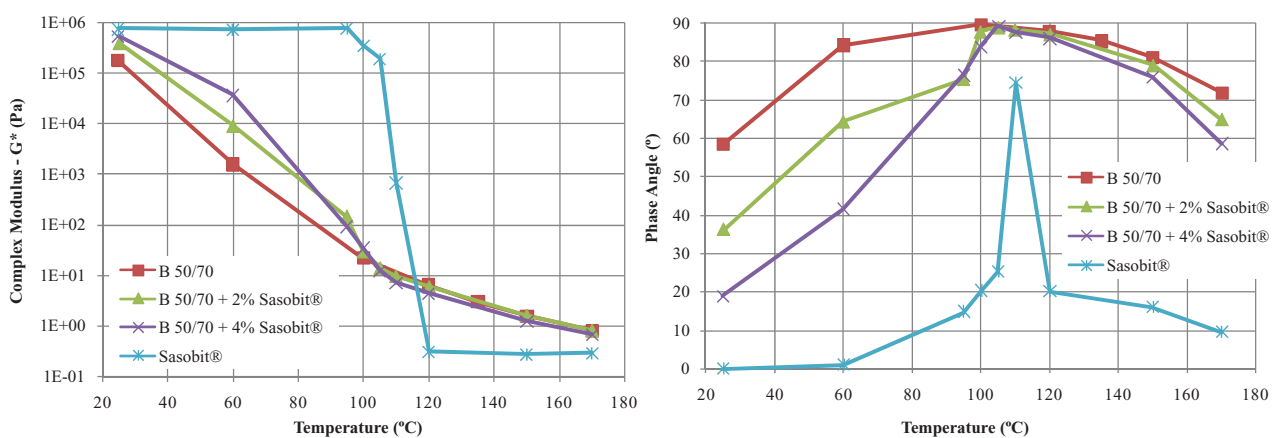

Figure 11. Influence of the Sasobit ${ }^{\circledR}$ content in the rheological properties of the binder (DSR). 
25 and $100^{\circ} \mathrm{C}$. In fact, for those temperatures (and especially for temperatures near the R\&B softening point) the modified binder greatly increases its complex modulus and dynamic viscosity. The presence of Sasobit ${ }^{\circledR}$ in the modified binder increases its elasticity, reducing the phase angle values and restraining the purely viscous behaviour at temperatures above $100^{\circ} \mathrm{C}$. At higher temperatures (WMA production) only small differences of behaviour were noticed between the modified binder and the original bitumen.

In order to ease the analysis of the rheology results, a reference frequency of $1 \mathrm{~Hz}$ was selected to compare the different materials tested using DSR. Thus, Figure 11 shows the comparison of the rheological properties (complex modulus and phase angle) of the original bitumen 50/70, the modified binders produced with this bitumen (with 2 and $4 \%$ additive) and the pure Sasobit ${ }^{\circledR}$ additive.

It was observed that Sasobit ${ }^{\circledR}$ is essentially an elastic material (lower phase angles), except at temperatures near its congealing point $\left(102^{\circ} \mathrm{C}\right)$. Even when this additive becomes liquid, the elastic part of its complex modulus prevails. In contrast, the original bitumen presents essentially a viscous behaviour at $1 \mathrm{~Hz}$ over the evaluated temperatures. Modifying the original bitumen with Sasobit ${ }^{\circledR}$ mainly increases the elastic part of the complex modulus in direct proportion to the amount of additive used, which is essentially observed at operating temperatures $\left(25\right.$ to $\left.80^{\circ} \mathrm{C}\right)$. The reduction of the complex modulus and phase angle at application temperatures (above $120^{\circ} \mathrm{C}$ ) is a central objective of WMA additives, but only a minor decrease is obtained by comparing bitumens before and after Sasobit ${ }^{\circledR}$ modification. Thus, the highest quantity of Sasobit ${ }^{\circledR}(4 \%)$ studied should be used in the modified binder in order to ensure a major decrease of the complex modulus, maximizing the decrease of WMA application temperatures.

Previously, it was observed that a $50 / 70$ pen bitumen modified with $4 \%$ of Sasobit ${ }^{\circledR}$ can be considered as a 35/50 binder at in service conditions, as well as a 100/150 pen bitumen
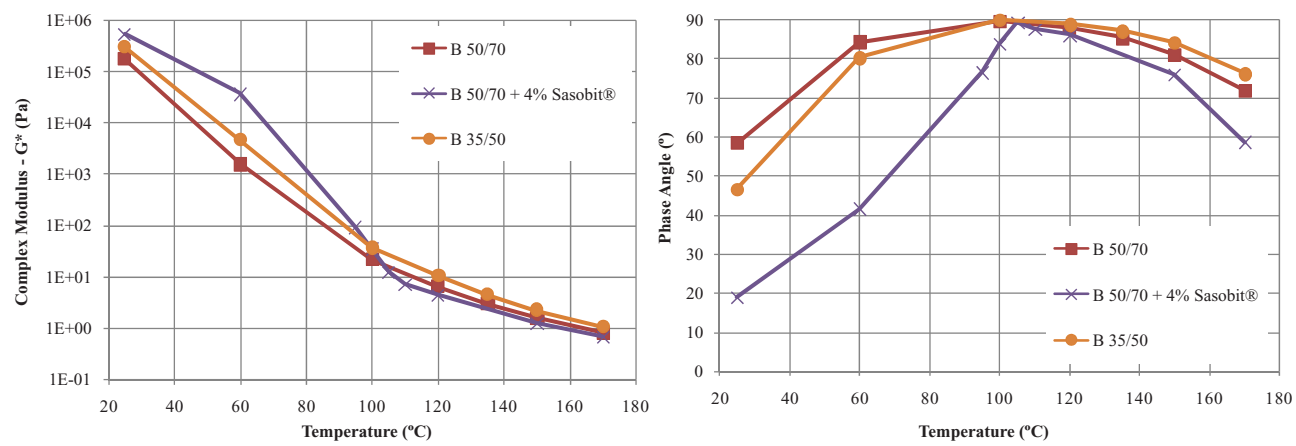

Figure 12. Rheological properties of a 35/50 bitumen vs a 50/70 Sasobit ${ }^{\circledR}$ modified binder (DSR).
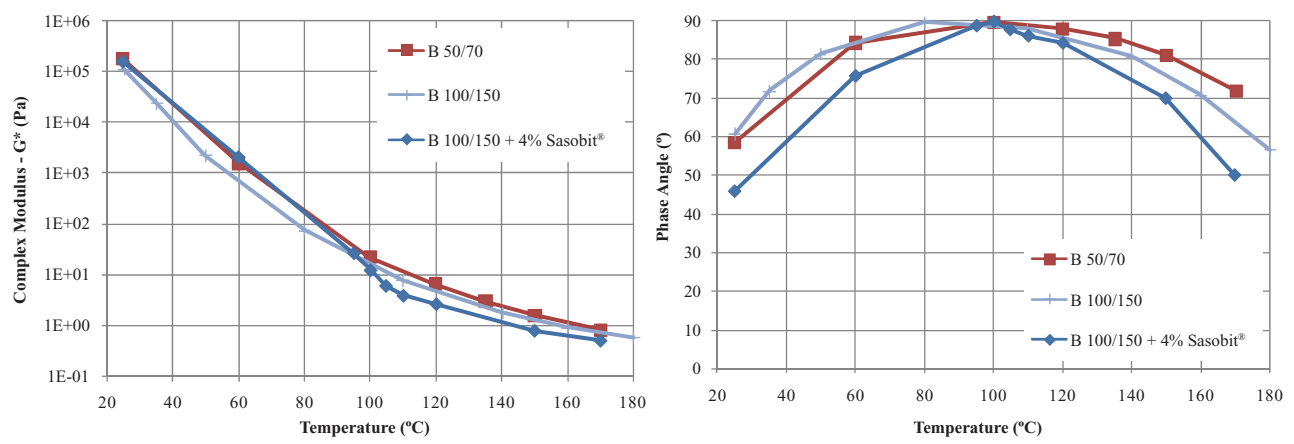

Figure 13. Rheological properties of a 50/70 bitumen vs a 100/150 Sasobit ${ }^{\circledR}$ modified binder (DSR). 


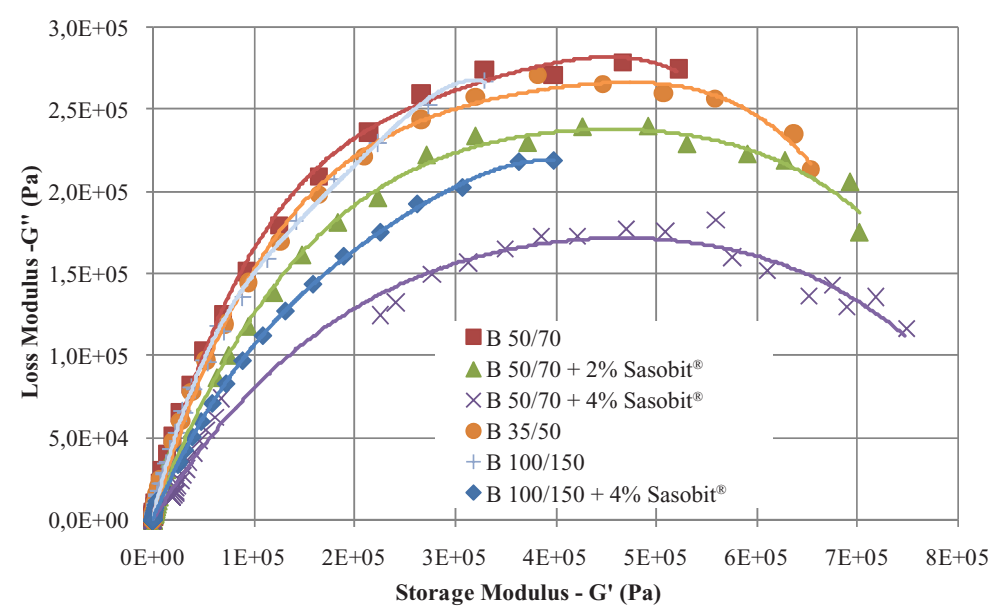

Figure 14. Cole-Cole plot of the studied binders based on their rheological properties (DSR).

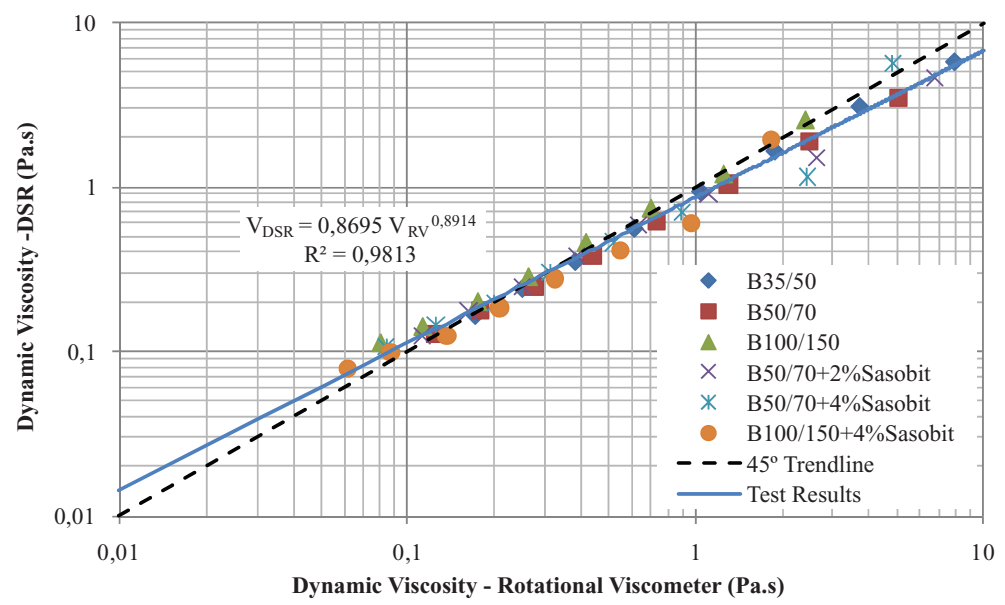

Figure 15. Relation between the viscosities measured in the rotating spindle apparatus and in the DSR.

modified with $4 \%$ of Sasobit ${ }^{\circledR}$ can be considered as a 50/70 binder. The comparison between the rheological properties (complex modulus and phase angle) of these binders is presented in Figures 12 and 13, respectively for the 50/70 and 100/150 modified binders $\left(4 \%\right.$ of Sasobit $\left.{ }^{\circledR}\right)$.

The complex modulus results confirm that the modified binders using softer bitumens have similar or even higher modulus than harder original bitumens, being thus possible to obtain a major reduction of the application temperature of the WMA mixtures and upholding operating properties comparable to the HMA mixtures. Moreover, it was observed that the Sasobit ${ }^{\mathbb{B}}$ modified binders, even being produced with softer bitumens, still have a higher elastic modulus (lower phase angle) in comparison with that of harder original bitumens. Soenen et al. (2008) reached similar conclusions for several wax modified binders.

The real part of the complex shear modulus $\left|G^{*}\right|$ is $G^{\prime}$ (storage modulus) and it is associated with the elastic part of the material behaviour. The imaginary part of the complex shear modulus is G" (loss modulus) and it is associated with the viscous part of the material behaviour. The Cole-Cole plot of the loss modulus vs the storage modulus of the different binders is illustrated in Figure 14, so as to evaluate the influence of the Sasobit ${ }^{\circledR}$ additive in the viscoelastic rheological behaviour of the binders at operating temperatures. It was observed that the viscoelastic behaviour is greatly influenced by the amount of Sasobit ${ }^{\circledR}$ added to the 
original bitumens, with a visible reduction of the viscous behaviour and a significant increase in the elastic behaviour of the modified binders. Although the maximum values of $\left|G^{*}\right|$ of the neat bitumens $(35 / 50,50 / 70$ and 100/150) are distinct, it was observed that the relation between their loss and storage moduli (related with their viscoelastic behaviour) is similar. This typical behaviour of the neat bitumens is truly changed into a more elastic behaviour after Sasobit ${ }^{\circledR}$ modification.

\subsection{Comparison with dynamic viscosity results of the rotating spindle apparatus}

One of the methodologies used in the present study for determining the dynamic viscosity of the binders at different temperatures is very simple (rotating spindle apparatus) and do not demand a very expensive equipment to carry out the tests (like DSR). However, reference to such an approach was not found in the literature and, therefore, a comparison with a traditional methodology was necessary to assess whether it could be used more often to study the evolution of binder viscosity with temperature. The results obtained in both test types, for the conventional and the Sasobit ${ }^{\circledR}$ modified binders, are plotted together in Figure 15. The points situated on the $45^{\circ}$ (dashed) line show similar results for both types of test. In fact, a good correlation between most of the points obtained can be observed, what indicates that if a DSR is not available the new methodology may be used in the future. Nevertheless, it was noticed that for temperatures below $120^{\circ} \mathrm{C}$ the rotational viscometer presents viscosities slightly higher than the DSR, occurring the opposite at temperatures above $160^{\circ} \mathrm{C}$.

\section{ASSESSMENT OF THE AFFINITY BETWEEN AGGREGATES AND BINDERS}

In order to assess whether the use of the studied additives in the modification of the conventional binders would contribute to an increase in the water sensitivity of the final mixtures, a procedure indicated in the EN 12697-11 standard, regarding the affinity between aggregates and binders, was used. In this test, the aggregate used was obtained from a quarry next to a site where a trial was to be made, later in this project. Therefore, it was not possible to analyse the influence of using a different aggregate on the water sensitivity of the mixture. Thus, the results are significantly affected by the aggregate used, as it can be observed in Figure 16.

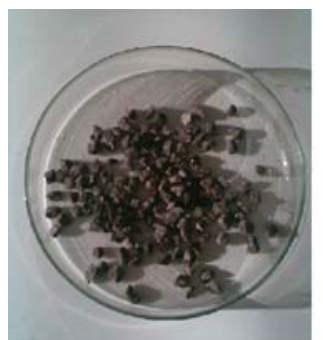

Control mixture (8\%)

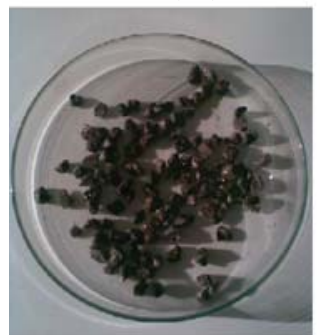

Mixture with 4\% "Sasobit" (7\%)
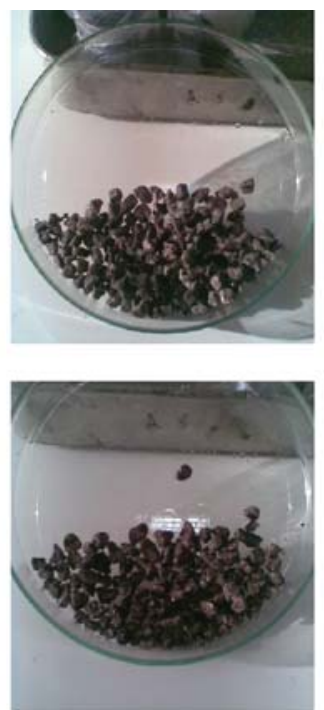

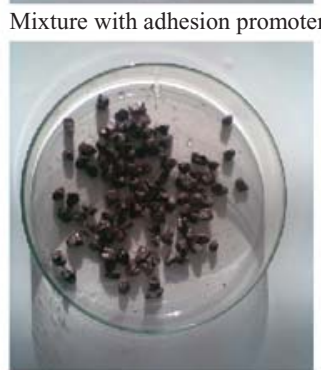

Mixture with $0.3 \%$ "Cecabase" $(6 \%)$
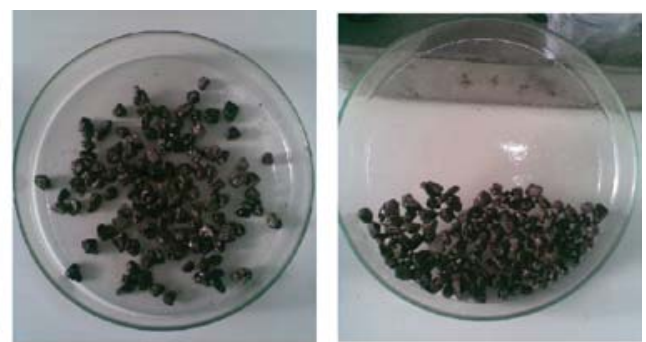

"Interlene" (30\%)

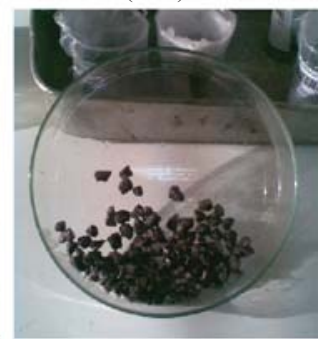

$(6 \%)$

Figure 16. Results of the affinity tests obtained from the studied binders. 
In fact, only $8 \%$ of the aggregate surface was covered by bitumen for the conventional mixture produced with $5 \%$ of a $50 / 70$ pen bitumen. An adhesion promoter additive ("Interlene") was therefore used to enhance the behaviour of the mixture, resulting in an increase of the aggregate surface covered by bitumen from 8 to $30 \%$. The results of the "modified" binders (with the amount suggested by the previous results and the producers recommendations, i.e. $4 \%$ Sasobit $^{\circledR}$ and $0.3 \%$ Cecabase $^{\circledR}$ ) were not significantly affected (7 and $6 \%$ of the aggregate surface covered by binder, respectively) in comparison with the control mixture.

\section{CONCLUSIONS}

This paper presents the preliminary results of an ongoing project where the use of binder additives to reduce the temperature of the production and application of bituminous mixtures is being assessed. This project will involve the evaluation of the reduction in GHG emissions of two WMAs in comparison to a conventional HMA and the assessment of their mechanical properties. The results obtained up to the present date allow drawing the following conclusions:

- the modified binders did not show significant problems of affinity to the aggregate studied, in comparison with the conventional binder;

- it was also observed that only Sasobit ${ }^{\circledR}$ changes the viscosity of the binder;

- the Sasobit ${ }^{\circledR}$ additive mainly increases the elastic part of the complex modulus proportionally to the amount of additive used;

- the Sasobit ${ }^{\circledR}$ additive essentially modifies the bitumen rheological properties at operating temperatures (between 25 and $80^{\circ} \mathrm{C}$ );

- a maximum temperature reduction of $15^{\circ} \mathrm{C}$ was achieved using $4 \%$ of Sasobit ${ }^{\circledR}$ with a softer binder;

- a good correlation was found between the dynamic viscosity results obtained with the DSR and the Rotating Spindle Viscometer at different temperatures.

\section{REFERENCES}

Button, J.W., Estakhri, C. and Wimsatt A. 2007. A Synthesis of Warm-Mix Asphalt. Texas Transportation Institute and Federal Highway Administration. Report 0-5597-1. Texas.

CECA 2008. Green Road Formulation-Warm Mix Asphalt-Cecabase RT. Ceca, Arkema Group. $<$ http://www.cecachemicals.com/sites/ceca/en/business/bitumen_additives/warm_coated_material/ warm_coated_material.page > (Accessed on 4Nov08).

D’Angelo, J., Harm, E., Bartoszek, J., Baumgardner, G., Corrigan, M., Cowsert, J., Harman, T., Jamshidi, M., Jones, W., Newcomb, D., Prowell, B., Sines, R. and Yeaton, B. 2008. Warm-Mix Asphalt: European Practice. Federal Highway Administration, U.S. Department of Transportation, American Association of State Highway and Transportation Officials, National Cooperative Highway Research Program, Report no. FHWA-PL-08-007. Alexandria.

Hurley, G.C. and Prowell, B.D. 2005. Evaluation of Sasobit ${ }^{\circledR}$ for use in Warm Mix Asphalt. National Center for Asphalt Technology, Auburn University, NCAT Report 05-06. Auburn.

Hurley, G.C. and Prowell, B.D. 2006. Evaluation of Potential Processes for Use in Warm Mix Asphalt. Journal of the Association of Asphalt Paving Technologists, Vol. 75: 41-90.

Park, K., Hwang, Y., Seo, S. and Seo, H. 2003. Quantitative Assessment of Environmental Impacts on the Life Cycle of Highways. Journal of Construction Engineering and Management, American Society of Civil Engineers. Vol. 129 (1): 25-31.

Sasol Wax GmbH 2004. The Bitumen Additive for Highly Stable Easily Compactible Asphalts. Sasobit ${ }^{\mathbb{B}}$ Product Information 124. Sasol Wax GmbH. Hamburg.

Sasol 2008. Sasobit Technology. Sasol Wax. <http://www.sasolwax.com/Sasobit_Technology.html> (Accessed on 4Nov08).

Soenen, H., Tanghe, T., Redelius, P., de Visscher, J., Vervaecke, F. and Vanelstraete, A. (2008). A Laboratory Study on the Use of Waxes to Reduce Paving Temperatures. 4th Eurasphalt \& Eurobitume Congress. Copenhagen. 
